\title{
Academic Mobility and Intercultural Pathways for Knowledge Transfer
}

\author{
Liudmila Kirpitchenko \\ European University Institute, Florence, Italy
}

\begin{abstract}
This article focuses on academic mobility with the view of examining intercultural relations and knowledge flows. Academic mobility refers to the global mobility and exchange of tertiary students and university staff, which is a growing phenomenon worldwide. This article seeks to highlight additional possibilities for exploring effective intercultural pathways for knowledge mobility, translation and transfer that are created through academic mobility. Academic migrants in particular have been acknowledged as important agents of intercultural knowledge transfer, interchange and knowledge creation. This paper sets up the theoretical parameters for exploring intercultural knowledge flows within academic mobility. It explores diverse aspects of intercultural encounters to reveal underlining conditions for effective knowledge transfer and knowledge creation between cultures. The theoretical notions and ideas discussed provide the foundations for subsequent ethnographic research which form the basis of this paper: a pilot survey conducted among academic migrants at two international educational institutions in Italy. This survey sought to analyse empirical manifestations of cosmopolitanism in everyday intercultural academic interactions, as preconditions for successful knowledge transfer, interchange and ultimately, knowledge creation.
\end{abstract}

Keywords: Academic mobility, cosmopolitanism, cultural capital, habitus, intercultural dispositions, knowledge transfer.

\section{Introduction}

The focus of this paper is academic mobility as a platform for examining intercultural knowledge flows and effective cultural pathways for knowledge transfer. Academic mobility refers to the international transportability and exchange of tertiary students and university staff, which is a growing phenomenon worldwide. The expanding European Union hosts many programs for academic mobility exchanges, such as Erasmus, Socrates, Marie Curie, Tempus and others. At the same time, the leading immigrant-receiving countries, such as Australia, have enhanced their immigrant recruitment techniques to attract highly educated, skilled and experienced individuals ${ }^{1}$. Academic mobility creates additional possibilities for knowledge translation and transfer, and so academic migrants have become very important agents in processes of knowledge transferral, interchange and creation.

${ }^{1}$ G.Hugo. 'Globalization and Changes in Australian International Migration'. Journal of Population Research, 23 (2), 2006, pp. 107-134. 
Academic mobility may not be a new phenomenon, but popular awareness of it has grown after student exchange programs were introduced within the evolving and expanding European Union of the late 1980s. In the context of this research, academic mobility is defined as the transnational movement of university students and staff for learning and teaching assignments, which has manifested in the "European Community Action Scheme for the Mobility of University Students" programme, or "Erasmus". Erasmus started in Europe in 1987 as a program for student exchange. In the first year, 3,244 students from 11 countries spent a study period abroad. The program grows every year and in 2012-2013, close to 270,000 students and more than 52,000 staff from 33 European countries participated in Erasmus exchanges ${ }^{2}$. Nowadays the European Union hosts many other programs for academic exchanges. Erasmus remains the most well-known and widespread in Europe, and with its newer addition - "Erasmus Mundus" - it now involves the academic community not only from Europe, but from around the globe.

This paper explores growing mobilities and diverse aspects of intercultural dialogue with an objective to reveal conditions for successful cultural knowledge transfer and creation. For this pilot qualitative study, academic migrants at two international educational institutions in Italy - European University Institute (EUI) and LUISS Guido Carli (Free International University of Social Sciences) - were invited to share their experiences, views and perceptions of intercultural communication, aiming to produce a better understanding of the symbolic processes in which people from different cultures exchange knowledge and create shared meanings. An objective of this study is to examine the socio-cultural conditions that enable knowledge transfer and the creation of shared meanings: this paper presents the theoretical thinking which underlies the study in progress and analyses evolving empirical manifestations of cosmopolitanism in everyday intercultural interactions. It discusses the theoretical concepts and ideas that prompted the researcher to test this study's hypothesis that postmodern cosmopolitan milieu facilitate intercultural integration, knowledge transfer and knowledge creation. Some preliminary results of the pilot ethnographic research are also presented and analysed.

\section{Culture and Knowledge Mobility}

Growing numbers of academic mobilities have created new economic opportunities that have recently been termed "edu-business" when governments approach education as a business opportunity.3 Additionally, global mobilities of people present opportunities for intercultural enrichment and knowledge transfer, 4 and it is this aspect is the focus of this research. In the field of social sciences, culture has many interpretations, 5 yet all agree that culture plays a pivotal role in any social form

\footnotetext{
${ }^{2}$ European Commission (EC) 'Erasmus Facts, Figures \& Trends The European Union support for student and staff exchanges and university cooperation in 2012-2013', European Commission Website, 2014. At: http://ec.europa.eu/education/library/statistics/ay-12-13/facts-figures_en.pdf, accessed May 2015. 3S. J. Ball, Global Education Inc.: New Policy Networks and the Neoliberal Imaginary. London and New York: Routledge, 2012, pp.116-136.

4R. Bedford, E. S. Ho, \& J. Lidgard, 'From Targets to Outcomes: Immigration Policy in New Zealand, 1996-2003' in A. Trlin, P. Spoonley, N. Watts, (Eds.), New Zealand and International Migration: A Digest and Bibliography, Vol. 4. Palmerston North: Massey University Printery, 2005, pp. 1-43.

5C. Barker, Making Sense of Cultural Studies. London: Sage Publications, 2002, pp.66-85.
} 
of human interaction.6 The formal definition of culture in this sense was provided by Edward B. Tylor:

Culture or civilisation, taken in its wide ethnographic sense, is that complex whole which includes knowledge, belief, art, morals, law, custom, and any other capabilities and habits acquired by man as a member of society.7

The use of culture in wide collective, anthropological and holistic terms is growing globally, thus UNESCO describes culture as follows:

Culture should be regarded as the set of distinctive spiritual, material, intellectual and emotional features of society or a social group, and that it encompasses, in addition to art and literature, lifestyles, ways of living together, value systems, traditions and beliefs. ${ }^{8}$

UNESCO also notes that "culture is at the heart of contemporary debates about identity, social cohesion, and the development of a knowledge-based economy." 9 Based on the preceding definitions, this study will conceptualise culture broadly as a holistic "way of life." From a theoretical perspective, knowledge is inseparable from culture, and thus knowledge is embedded in the culture of the individual ${ }^{10}$. This study adopts a broad, anthropological definition of culture based on notions of collectivity and the socialisation of individuals through everyday knowledge, cultural norms, traditions and expressions. ${ }^{11}$

\section{Knowledge Creation and Cultural Capital}

Cultural capital is defined as combining diverse forms of knowledge, skills, education, and high expectations. ${ }^{12}$ Like other forms of capital, cultural capital serves as a power resource, or a way for groups to maintain social status and acquire higher social positions. ${ }^{13}$ Within the concept of cultural capital, Bourdieu distinguishes an "embodied state or cultural habitus" which describes the "long-lasting dispositions of the mind and body." ${ }^{14}$ This form of cultural capital is formed by the processes of socialisation and enculturation, which describe the ways how cultural capital becomes embodied in a person's character, personality and perspective. It is this "embodied state of cultural capital" that is particularly significant for this paper, which looks at everyday intercultural encounters in academia. The embodied state of culture, also known as "cultural habitus", is particularly important as it is revealed in everyday interactions and is subject to daily interpretations. "Habitus" refers to the totality of learned habits, bodily skills, styles, tastes, and other non-discursive knowledges that might be said to "go without saying" for a specific group, and in this

\footnotetext{
${ }^{6} \mathrm{G}$. Markus, 'Culture: The Making and the Make-up of a Concept (An Essay in Historical Semantics)'. Dialectical Anthropology, 18, 1993, pp. 3-29.

7E. B. Tylor, The Origins of Culture. New York: Harper and Row, 1958, p.1.

8UNESCO. Universal Declaration on Cultural Diversity. Paris, 2001, At: http://portal.unesco.org/, accessed May 2015.

9ibid.

${ }^{10}$ E. B. Tylor, op.cit.

${ }^{11}$ ibid.

${ }^{12}$ P. Bourdieu. Forms of Capital. In J. G. Richardson (Ed.), Handbook of Theory and Research for the Sociology of Education, pp. 241-258. New York: Greenwood Press, 1986, pp. 243 ff.

13D. Swartz, Culture and Power: The Sociology of Pierre Bourdieu. Chicago: University of Chicago Press, 1997, pp.65-94.

14P. Bourdieu, 'Forms of Capital', op. cit., p. 243.
} 
way can be said to operate beneath the level of consciousness. As Bourdieu defines it, habitus is:

a system of durable, transposable dispositions, structured structures predisposed to function as structuring structures, that is, as principles of the generation and structuring of practices and representations... ${ }^{15}$

Habitus therefore designates "a way of being, a habitual state (especially of the body) and, in particular, a predisposition, tendency, propensity, or inclination" 16 and describes non-discursive aspects that are significant in intercultural encounters.

Habitus concerns the unconscious aspects of one's culture. As a learned state, habitus originates from and relates to the past of the individual, group, society or nation, ${ }^{17}$ and is understood as "a matrix of perceptions, appreciations, and actions" ${ }^{18}$ Referring to the collective acquisition of learned habits and knowledge, habitus encompasses the ways in which society becomes "deposited in persons in the form of lasting dispositions, or trained capacities and structured propensities to think, feel, and act in determinate ways", which then "guide them in their creative responses to the constraints and solicitations of their extant milieu". ${ }^{19}$ Thus, habitus focuses on the non-discursive aspects of culture; the term "unconscious cultural" describes phenomena that cannot be identified.

According to Bourdieu, cultural patterns are deeply entrenched and unconsciously held, meaning that cultural beliefs can be perceived as clear markers for cultural distinction ${ }^{20}$. As Reay explains; "habitus helps to make visible the taken-for-granted inequalities of gender, "race" and class embedded in such social processes." 21 The concepts of cultural capital and habitus are both central to this paper, as they can be used to illustrate the role culture plays in knowledge exchange, transfer and creation.

Both cultural capital and habitus indicate that knowledge is culturally embedded, meaning that all types of knowledge are culturally relative. Classifications of diverse forms of knowledge developed by Collins ${ }^{22}$ and Blackler ${ }^{23}$ show interrelations between capital, habitus and knowledge. Collins illustrates the basics of knowledge transfer by describing how straightforward this process is for a computer: "When one takes the knowledge from one computer and puts it in another, the second computer 'becomes' identical to the first as far as its abilities are concerned." 24 He observes that this process is more complex among humans, and by developing what he calls "the structure of knowledge" he shows the difference between "tacit" knowledge, that is

\footnotetext{
15P. Bourdieu. Outline of a Theory of Practice. New York: Cambridge University Press, 1977, p. 72. 16ibid., p. 214.

17ibid.

18ibid., pp. 82-83.

19L. Wacquant, 'Habitus' in J. a. M. Z. Beckert, (Ed.) International Encyclopaedia of Economic Sociology, London: Routledge, 2005, pp. 315-319.

2oibid.

${ }^{21}$ D. Reay. “They Employ Cleaners to Do That”: Habitus in the Primary Classroom'. British Journal of Sociology of Education, 16, 1995, pp. 369.

${ }^{22}$ H. M. Collins, 'The Structure of Knowledge'. Social Research: An International Quarterly, 60 (1), 1993, 95-116; H.M. Collins, 'Tacit Knowledge, Trust and the Q of Sapphire'. Social Studies of Science 31(1), 2001, pp. 71-85. ${ }^{23}$ F. Blackler, 'Knowledge, Knowledge Work and Organizations: An Overview and Interpretation'. in The Strategic Management of Intellectual Capital and Organizational Knowledge, Ed. by C.W. Choo \& N. Bontis, Oxford: Oxford University Press, 2002. pp. 47-64.

${ }^{24 H}$. M. Collins. 'The Structure of Knowledge', op. cit., p. 96.
} 
knowledge that appears to be located in society, and "formal" knowledge, which can be transferred in symbolic form and encoded into machines and other artefacts. ${ }^{25}$ Blackler expands upon this typology and suggests that knowledge can be classified as "embrained", “embodied", "encultured", "embedded" or "encoded". He categorises these as follows:

- Embrained knowledge refers to abstract knowledge, which innately responds to underlying cultural patterns.

- Embodied knowledge is acquired by solving problems based on intimate knowledge of a particular situation, rather than abstract rules.

- Encultured knowledge refers to the shared cultural understandings that are achieved through processes of socialisation and acculturation.

- Embedded knowledge resides in systemic routines, roles, formal procedures, and organisational cultures.

- Encoded knowledge is conveyed in the traditional forms of knowledge, exemplified by books, manuals, codes of practice and websites within a certain culture. ${ }^{26}$

This typology extends the theoretical arguments of Bourdieu on capital and habitus and illustrates some practical applications of knowledge exchange and creation. For example, embrained, encultured and encoded knowledges strongly reflect the patterns and mores of an individual's own culture. Embodied and embedded knowledge reflects individual experiences and practices in particular settings, and relate more to organisational working experiences. Therefore, while the former group requires reflexive interaction through the creation and understanding of shared cultural meaning, the latter are easily transferable in more formal settings and practices. This paper seeks to identify which cultural dispositions are conducive for knowledge transfer and knowledge creation in various intercultural situations and environments.

\section{Cosmopolitan Outlooks}

In this project, the role culture plays in the intercultural communication process is analysed against a backdrop of contemporary debates on post-modernity and cosmopolitanism. These debates share a central feature; a clear emphasis on diversity and plurality of viewpoints. As Giddens states, "The postmodern outlook sees a plurality of heterogeneous claims to knowledge." 27 Individual life trajectories are no longer bound by the traditional imperatives and social anxieties in constructing and maintaining self-identities. Individual life trajectories are now conceived as more open and flexible undertakings. ${ }^{28}$ Writing about postmodern cosmopolitan society, Beck suggests that difference is internalised through "the copresence and coexistence of rival lifestyles, contradictory certainties in the

25ibid., p. 116.

${ }^{26} \mathrm{~F}$. Blackler, op. cit., pp.48-49.

27A. Giddens, The Consequences of Modernity. Stanford, California: Stanford University Press, 1990, p. 2.

${ }^{28}$ A. Giddens, Modernity and Self-Identity: Self and Society in the Late Modern Age. Stanford, California:

Stanford University Press, 1991, pp.35-69. 
experiential space of individuals and societies." 29 He refers to the creation of a new world order, "in which it became necessary to understand, reflect and criticise difference, and in this way to assert and recognise oneself and others as different and hence of equal value." 30 Thus, both post-modernity the cosmopolitan theory pave the way to notions of mutual recognition, understanding and respect of cultural otherness.

This research is guided by Beck's central defining characteristic of a cosmopolitan perspective which is "dialogic imagination." 31 This term signifies an entering into imaginative conversation with those from diverse cultures; in other words, a dialogue with the "other". Dialogic imagination thus refers to the appropriation and internalisation of different cultures and perspectives, and ultimately the creation of the "internalised other." 32 It corresponds to the coexistence of different ways of life that rival the individual experience. Dialogic imagination emphasises the need to compare, reflect, accept, understand, and combine what appears to be contradictory certainties. The cosmopolitan perspective is an imagination of alternative cultures, rationalities and ways of life, which integrate the "otherness" of the other.33 Beck puts such processes under the umbrella of "interculturation", which refers to the notion that "every culture exists side by side in combination, comparison, contradiction and competition in every aspect of human experience." 34 These processes of interculturation are meant to continue as global cultural interactions and exchanges are inevitable and they have been intensifying.

Further, this research is based on the methodological applications of cosmopolitanism and the way cosmopolitanism is redefining the sociological frame of reference. Three defining features of a concept of cosmopolitanism are globality, plurality and civility. 35 Globality describes openness to the world, awareness of a globally defined sphere of responsibility, and globally shared collective futures. Plurality is an acknowledgement of the otherness of others and commitment to "stimulate the self-reflexivity of divergent entangled cosmopolitan modernities". Civility defines commitment to dialogue and non-violence.

Departing from these three fundamental features - globality, plurality and civility this study approaches cosmopolitanism as espousing open-ended and welcoming dispositions. Following Beck, Hannerz proposed what has become the key definition of cosmopolitanism as an "orientation, a willingness to engage with the other ... intellectual and aesthetic openness toward divergent cultural experiences, a search for contrasts rather than uniformity" ${ }^{6}$ Calcutt, Woodward \& Skrbis draw on this definition and suggest that "cosmopolitanism includes Kantian universalism, crosscultural competence, and either a willingness to tolerate or engage with otherness". 37 The idea that "willingness to engage with the other" leads to better societal-wide

\footnotetext{
29 U. Beck, The Cosmopolitan Vision. Cambridge, UK: Polity Press, 2006, p. 89.

30 ibid.

${ }^{31}$ U. Beck, 'The Cosmopolitan Society and Its Enemies'. Theory Culture Society 19, 2002, pp. 17-44.

32 ibid., p.18.

33 ibid., pp. 18-19.

34 ibid., p.18.

35 ibid., pp. 35-36.

${ }^{6} 6$ U. Hannerz, Transnational Connections: Culture, People, Places. New York: Routledge, 1996, p. 104.

37 L. Calcutt, Woodward, I. \& Skrbis, Z. 'Conceptualizing otherness: An exploration of the cosmopolitan schema'.

Journal of Sociology, 45 (2), 2009, p. 172.
} 
outcomes is central in a very influential work conducted by Florida ${ }^{3}$ on global competition for talent. Skrbis \& Woodward point out a central dimension of cosmopolitanism adding that "cosmopolitans espouse a broadly defined disposition of "openness" toward others, people, things and experiences whose origin is nonlocal".39 These definitions of cosmopolitanism formed a foundation for designing a pilot study as a precursor for this study to test empirically the promises of cosmopolitanism which have been largely theoretical in nature.

Pilot ethnographic research had an objective of testing in practice whether mobile academics tended to display certain cosmopolitan dispositions that aided them to being successful in intercultural interactions and professional communication. Cultural dispositions describing "long-lasting dispositions of the mind and body"40 that individuals display in relations with others, were found to be the crucial components of successful intercultural dialogue. This paper hypothesises that cosmopolitan dispositions facilitate and promote intercultural dialogue, knowledge transfer and creation of shared cultural meanings.

Being attuned to different cultures on many levels has been considered a necessary cultural attribute in the age of modernity. Cultural openness involves "the search for, and delight in, the contrasts between societies rather than a longing for superiority or for uniformity". ${ }^{41}$ Cultural openness is the main characteristic of cosmopolitan disposition, a stance that may be conducive to generating new forms of critical knowledge. ${ }^{2}$ Cosmopolitanism has to entail universal ethical commitments and "a distinct ethical orientation towards selflessness, wordiness, and communitarianism." 43 This pilot empirical research examined theoretical interpretations of cosmopolitanism and set an objective of locating cosmopolitan values and dispositions in everyday discourses, situations and experiences of interpersonal interactions in academia. This paper presents preliminary empirical testing and discussion of cosmopolitan dispositions which were found to be preconditions for successful knowledge exchange, knowledge transfer and knowledge creation. The central hypothesis of this study is that various expressions of cosmopolitan dispositions present an opportunity of viewing cosmopolitanism as a desirable prerequisite for intercultural dialogue in the age of post-modernity.

\section{Internationalised Academia}

An objective of this discussion is to examine the empirical evidence of the growing cosmopolitan values and dispositions in everyday academic interactions. For this purpose, two highly acclaimed international academic institutions were chosen. Empirical research on academic hyper-mobility was conducted on the premises of two perfect sites for examining the experiences of mobile academics of the post-

\footnotetext{
$3^{8}$ R. Florida. The Rise of the Creative Class: And How It's Transforming Work, Leisure, Community and Everyday Life. New York: Basic Books, 2002; R. Florida, The Flight of the Creative Class: The New Global Competition for Talent. New York: Harper Collins Business, 2005.

39 Z. Skrbis \& I. Woodward, 'Investigating the Idea of Cosmopolitan Openness: Strategies, Repertoires and Practices', Sociological Review 55(4), 2007, p. 730.

$4^{40}$ P. Bourdieu, 'Forms of Capital', op. cit., p. 243.

${ }^{41}$ J. Urry, 'The Global Media and Cosmopolitanism'. Transnational America Conference: Bavarian American Academy, Munich: Department of Sociology, Lancaster University, UK, 2000, p. 7.

42 U. Hannerz, op. cit., pp. 103-109.

43 G. Kendall, I. Woodward, \& Z. Skrbis, The Sociology of Cosmopolitanism: Globalization, Identity, Culture and Government. London: Palgrave MacMillan, 2009, p. 22.
} 
modern times in a cosmopolitan academic milieu: the European University Institute (EUI) in Florence and LUISS Guido Carli University in Rome, both in Italy. The EUI is an international educational institution overseen by the European Union. LUISS Guido Carli stands for Libera Università Internazionale degli Studi Sociali, which is translated as Free International University for Social Studies. Both the EUI and LUISS attract large numbers of international students and staff. Both universities are synonymous with academic mobility internationally and represent a vivid example of liquid academic mobility. Their academic environments provide an excellent opportunity to explore how social and intercultural interactions develop among academic professionals.

The researcher's lengthy stays as a Visiting Scholar at the EUI and LUISS provided her with ample opportunities to participate in all types of educational activities: lectures, classes, seminars, conferences and recreational events. She was thus able to experience academic research environments enriched by a unique cross-fertilisation of research traditions and academic approaches. The EUI and LUISS are leading research and teaching institutions devoted exclusively to social sciences. They especially emphasise comparative studies and international links which are of particular interest for academic migrants. Both are renowned academic institutions which promote academic mobility by recruiting their full-time teaching staff, fellows and research students from all countries of the European Union and many other parts of the globe.

Overall, many participants described the EUI and LUISS environments as being international and/or cosmopolitan. For instance, one mobile academic with plentiful international experiences was adamant about the EUI international environment: "I have here $95 \%$ of students from all around the globe". As did many others, one international postgraduate researcher explained that there was no monolithic academic culture at the EUI: "Professors here are from different places". The teaching cultures of both universities were described as being heterogeneous and very diverse. This type of environment, which can be defined as international, intercultural or cosmopolitan, created a supportive milieu. It allowed many participants to enjoy intercultural communication which made knowledge sharing a successful practice.

For this study, research data were collected utilising the qualitative techniques of participant observation, focus groups and in-depth interviews. As a crucial part of the fieldwork, the researcher carried out valuable insider's research by partaking in diverse doctoral and post-doctoral training activities, both as a participant and an observer. This method allowed the researcher to gather plentiful qualitative data on students' learning experiences by participating and observing academic presentations, discussions and debates. The EUI and LUISS presented exceptional opportunities for exploring academic intercultural dialogue through first-hand interaction with mobile academic participants - post-graduate researchers, postdoctoral fellows and professors from many countries who became directly engaged in the fieldwork research.

\section{Cosmopolitan Dispositions}

Ethnographic participatory research revealed important findings on the growing perceptions of cosmopolitan outlooks and dispositions in everyday social 
interactions among mobile academics. The underlying idea of this discussion is that various expressions of cosmopolitan dispositions are desirable preconditions for successful knowledge exchange, knowledge transfer and knowledge creation. Two cosmopolitan dispositions that became salient in the fieldwork research are discussed in this section. They are firstly willingness to engage, referring to deeper interpersonal engagement, along with an accompanying notion of minimal power distance; and secondly openness to cultural diversity, described otherwise as intercultural acceptance.

This research tests whether cosmopolitanism provides a framework for mutually including diverse cultural patterns, which may be seen previously as mutually exclusive oppositions. It seeks to substantiate an argument that cosmopolitan values, including openness to cultural diversity, willingness to engage, and cultural acceptance, create mutually beneficial conditions for the effective transfer and creation of all types of knowledge. The empirical value of this research is seen in engaging a group of academic migrants to share their experiences, views and perceptions of intercultural communication, with a goal of producing a better understanding of the symbolic processes in which people from different cultures create shared meanings. One of the objectives of this study is to examine sociocultural conditions enabling knowledge transfer and creation of shared meanings. This research tests whether a postmodern cosmopolitan milieu facilitates intercultural integration and enables knowledge transfer and creation of shared cultural meanings.

The pilot interviews revealed that cosmopolitan dispositions tend to be found among academic migrants. Thus the notions, which can be described as willingness to engage or more profound interpersonal engagement, have featured as profound sentiments among respondents. The desire to be socially involved often sparked out of the perceived greater isolation and emotional detachment that almost every respondent felt at the beginning of their stay abroad. Thus, Galina lamented that her status was a visiting researcher did not allow her to take a very active part in the educational activities and she was not very much involved in the academic life of the university. She explained: "My expectations were higher ... I wanted to be more actively involved. For example I began attending seminars ... Then I went to [another university] for six months and I was really involved there. I was a part of the working group and so on. It was much easier there". Similarly, Alena admitted: "For me it really disturbed me to be lonely and be by my own. Maybe that's why I don't like my Ph.D. work because I think it gets very-very lonely. It is a lonely project and lonely thing. ... I like to be with a group of friends". Among successful strategies for intercultural communication, Alena said that it was very important for her to have the support of her friends and her family and people around her. She continued: "It is important to have good friends and people who can support you - your friends or someone you can talk to: your professor, or supervisor, or maybe somebody else your boss, somebody who can advise you what to do, so you are not left on your own. This is very important not to be lonely because you'll get depressed and want to give up, or feel like giving up."

The positive changes that everyone desired were described in terms of developing closer connections to other people and having a network of people to rely on and help each other. It was an interesting observation that in general, respondents found that communication between people becomes easier as hierarchical relations become less 
pronounced. A level of hierarchy in a society can be measured by a notion of power distance. The term Power Distance was proposed by Hofstede \& Hofstede 44 who included it among model indicators to measure cultural differences among different societies. The Power Distance index measures the degree of equality or inequality that exists in a society. While some societies do not allow significant upward mobility of its citizens, in other societies equality and opportunity for everyone is emphasised 45 . Relation to authority is one of the key traits that are embedded in the culture of the individual. It was also one of aspects of work and study relations that many respondents were keen to comment even in other segments of the interview without being guided by direct questions. Nick said that he was very lucky with his supervisor because he was given lots of independence and autonomy in his research work. Nick considered himself to be lucky to work in such collegial and friendly supportive environment.

Everyone from the people interviewed made an observation that there was less power distance between the students and professors. Authority in the cosmopolitan environment was, in Galina's words, "not very pronounced". She continued that unlike in her home country you could address any authority figure by their first name. In her country the Dean was "almost the god or someone very close to it". It was also Sofia's experience that when she did a PhD program the professors were her colleagues. Larisa had the same opinion that professors were even more open here. Compared to her home country, professors were closer to students and there was no strict separation between the professors and the students. She observed that judging by how professors communicated with her she did not feel that they were figures of authority. They were trying to be friendly and it was very different from her home: "Here because professors put themselves on the same level with you, it makes it easier to approach and talk to them."

Yana also believed that the relationship between students and professors were more formal in her home country. Here Yana placed more trust in her supervisor to guide her and give her ideas to go in one direction or another. Susan said that in her home country it was not easy to communicate with professors because they wanted you to book the time at least two weeks in advance: "It was very like you really felt that they are superior and they wanted to be superior to students and they kept their distance. ... There was certainly a hierarchy". Here it was the other way around and professors were more humane and gentler and there was no apparent hierarchy. Similarly, in his home country, Alex always felt subordination and a certain dependence because supervisors established a hierarchy according to which "they are your supervisor and you are nobody". In his view, in the cosmopolitan institutions there was a dialogue between students and professors: "When you are discussing your research project for example, you can debate and argue and defend your position. Your supervisor here can guide you not dictate you." Stefan lamented that for much of his career he was left alone. Stefan would have liked more team work and more discipline that would have let him produce more and more of better quality. In general he would have preferred to have a figure, like a father figure, who would tell you what was right to do and what not to do for your career but also for your research.

44 G. H. Hofstede \& G. J. Hofstede, Cultures and Organizations: Software of the Mind. New York: McGraw Hill, 2005.

45 ibid. 
An informal style of communication was noted in many daily aspects: from the dress code to the way authorities are addressed. Tania observed that in her native country, academic authority figures were addressed formally. It was not easy for Galina either to address her supervisor by their first name. She still preferred calling her supervisor "Professor such and such". Mark commented that the hierarchical differences were not that visible but that a lack of visibility might be only external and deceiving. Eva agreed that in academia, authority figures were very polite and correct. Furthermore, they did not exude a sense of superiority as some of the authority figures did at home. Many also noted that if relations on the horizontal level were more informal, it made communication easier. In the learning process many noted that less respect was given to authority and less reverence was shown for expert opinions. Students were encouraged to speak up in class and express their own ideas, whereas in a more hierarchical class setting students learned by memorizing and reproducing what authorities said on the subject. Many respondents praised this openness to diverse cultural expressions in academia.

\section{Openness to Cultural Diversity}

Other cosmopolitan dispositions that can be termed openness to cultural diversity or intercultural acceptance have found meaningful resonance in the interviews. Openness to cultural diversity and intercultural acceptance are key cosmopolitan dispositions according to many theoretical accounts. Among participants, there was a deep sense of global openness to the world diversity, awareness of a global opportunities and responsibilities, along with globally shared collective futures. Very high hopes and aspirations of the new possibilities opening up in the new countries this is what usually drives people to move from their home countries into the unknown. Stefan could not hide that he "was very fascinated about going to study at the international institution". Mark was equally enthusiastic: "My expectations were terrific and just unbelievable. I was going there with a lot of enthusiasm and great hopes. It was my first experience and I liked it. ... Everything was new and unusual and I enjoyed it." When Diana went abroad for the first time she described her prospects in even more brilliant terms: "My expectations were amazing. I thought that it was very important and it can even change my life, something along these lines."

Many respondents thought that their stay abroad would provide additional chances for their professional advancement. Nick explained that his reasons for going abroad were "mostly altruistic. Scholarly the libraries were very bad in my home country at that time and I was very interested in the literature for my dissertation which was not available in my country. ... Another reason was to meet scholars on my topic. My topic was quite narrow and in my home country there was only one scholar dealing with this topic." Larisa was also driven by the new challenges and wanted to "try other instructional and methodological approaches different from ours". Irina admitted that she was driven by her curiosity to learn about the educational systems abroad: "I wanted to learn something that I have not encountered before. It was always my main motivation. And I always wanted to compare both systems". Larisa also expressed her curiosity about the world: "I wanted to see the world and I expected to meet people from other countries." Sofia expected: "New life, better education ... I [expected] the usual stuff - better life, better education, a new world, and new friends." Eva also had a number of professional and personal hopes: "So that I will be able to develop myself not only in the academic sense, but also in the 
cultural sense". Eva's summarizing thoughts showed that people develop a variety of hopes and expectations in their multiple sides of everyday experiences, and that for them academic mobility provides unsurpassed exciting opportunities for realising their hopes for better living despite anticipated initial difficulties.

Intercultural acceptance presupposes that a plurality of viewpoints is recognised. It is an acknowledgement of the otherness of others and commitment to be self-reflexive of diverse cultures, no matter how entangled they may be in a cosmopolitan milieu. Many participants had favourable expectations of learning about many cultural imaginations. One female participant, Larisa, described enjoyment in interacting with people from different cultures in this way: "Their worldviews are different and you have to adjust to different viewpoints and it takes time to figure out that people are different. But it is also interesting to see how different viewpoints can be". Another female participant, Yana, also said that "it was genuinely interesting ... to hear someone speaking who experienced [diverse] societies and realities."

Similarly, Nick enjoyed the new culture very much: "everyone is very open and there are much more social and agitated people who care more about everything that is public. ... I can talk a lot about public and private things that I terribly enjoy". Mark also noted that preserving one's own cultural distinctiveness could be a great advantage. Alex agreed that "being different is not necessarily your drawback" and it was only a lack of adaptation that mattered, "but when you adapt, those differences can play on your behalf". He continued: "I cherish these differences. ... I am actually curious about cultural differences and it is a good challenge: How does this work in ... your culture? ... It is like languages - whenever you learn another language it enriches you". These words testify to the existing cosmopolitan dispositions that tend to surface in a cosmopolitan milieu.

Many participants were disposed to be considerate of culturally different contexts and manifestations. Irina said that in a new culture "you had to be prepared to be extra attentive to different situations. It is not like at home that you are familiar with everything. He had to be extra sensitive and attuned to differences". Irina was very happy with the level of socialising that existed here and with the personal relationships and social contacts that they had here. "Social environment is very pleasant as well here and it creates a sense of personal involvement and deeper connections with your colleagues. I like very much the social aspect of my [stay]". Susan felt that it is up to you how much you wanted to talk to your professors and they were very open and very helpful. Alex said that he felt "totally happy" precisely because the academic culture was so open. It was a general sentiment that recognition and acceptance of intercultural differences through the process of selfreflection led to the creation of a shared understanding of interpersonal communication.

\section{Conclusion}

This research paper discussed some of the theoretical ideas and notions that form the foundation for the ethnographic research in progress. It also presented insights from the pilot empirical study which uncovered some budding manifestations of evolving cosmopolitan dispositions within academic intercultural interactions. These included intercultural values, such as willingness to engage, also described as more profound interpersonal engagement, as well as openness to cultural diversity or intercultural 
acceptance. This paper views emerging cosmopolitan values as preconditions for success in knowledge exchange, transfer and creation. Some participants learned to thrive in the new self-described cosmopolitan culture and found it even to be more comfortable and enjoyable for them. For example, Sofia noted: "It is a different culture but it is probably in some ways better than [at home] in terms of acceptance and appreciation people have toward you. ... You feel different but I don't think it is a hindrance". Irina said that cultural differences had little salience when they are mediated by cosmopolitan dispositions. It was also becoming evident for the interviewees that cosmopolitan values of recognising and accepting intercultural differences through the process of self-reflection contributed to the creation of shared intercultural pathways for knowledge transfer. 